\title{
ALGUMAS LIÇÕES DO PROGRAMA DE ERRADICAÇÃO DO TRABALHO INFANTIL
}

Inaiá Maria Moreira de Carvalho

\begin{abstract}
Resumo: O artigo analisa o Programa de Erradicação do Trabalho Infantil - Peti, baseando-se principalmente na experiência do Estado da Bahia, considerada uma referência nacional. O texto também discute o significado do novo paradigma brasileiro de políticas sociais pela análise das condições operacionais do Programa, seus objetivos, limitações e benefícios.

Palavras-chave: crianças e adolescentes; trabalho infantil; programas sociais.
\end{abstract}

\begin{abstract}
This article analyses the Program of Eradication of Child Labor - Peti, mainly based on the experience of the state of Bahia, considered a national reference. The text also points out the meaning of the new Brazilian Social Politics paradigm through the analysis of the Program's operational conditions, objectives, limitations and benefits.

Key words: children and adolescents; child labor; social programs.
\end{abstract}

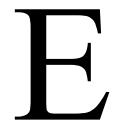

ste artigo analisa um dos principais programas da rede de proteção social implantados no Brasil na década de 90, o Programa de Erradicação do Trabalho Infantil - Peti, que vem retirando meninos e meninas entre 7 e 15 anos das consideradas "piores formas" desse trabalho.

Tão perversas quanto persistentes, as desigualdades sociais e a pobreza atingem particularmente a população infanto-juvenil no país. Conforme o último Censo Demográfico, $45 \%$ dessa população pertencia a famílias com uma renda per capita de até meio salário mínimo, porcentual que se elevava especialmente nos Estados menos desenvolvidos do Norte e Nordeste (UNICEF, s.d.). Essa pobreza contribui para que muitas crianças e adolescentes sejam expostos a diversas situações de risco, violência e exploração, entre outras, devido à inserção precoce no mundo do trabalho, muitas vezes em condições extremamente penosas e degradantes.

Em decorrência dessa situação, em 1992 o Brasil passou a fazer parte do Programa Internacional para a
Erradicação do Trabalho Infantil - Ipec, da Organização Internacional do Trabalho, e em 1994, foi criado e instalado o Fórum Nacional de Prevenção e Erradicação do Trabalho Infantil, sob a coordenação do Ministério do Trabalho com o apoio do Fundo das Nações Unidas para a Infância - Unicef e com a participação de organizações não-governamentais, empresários, representantes de sindicatos, da Igreja, do Poder Legislativo e do Judiciário. No segundo semestre de 1996, o Fórum Nacional lançou o Programa de Ações Integradas, que traçou o caminho para a implementação do Programa de Erradicação e Prevenção do Trabalho Infantil no país, orientado para o combate às chamadas "piores formas" desse trabalho, ou seja, aquelas consideradas perigosas, penosas, insalubres ou degradantes.

Com o apoio da OIT e do Unicef, o programa começou a operar em Mato Grosso do Sul, onde denúncias apontavam a existência de 2.500 crianças trabalhando na produção de carvão vegetal e vivendo em condições inaceitáveis. Pouco depois ele se estendeu aos Estados de 
Pernambuco e da Bahia, privilegiando, respectivamente, a zona canavieira e a região do sisal.

Envolvendo uma parceria entre governo federal, Estados e municípios, dando prioridade a áreas que utilizam o trabalho infantil em larga escala e em condições especialmente intoleráveis, ao longo dos anos o Peti se expandiu significativamente. Em 2000, ele já atendia a cerca de 140 mil crianças e adolescentes no país. Em 2001, houve um grande aumento e, em 2002 esse número chegou a 810.769, beneficiando 2.590 municípios em todos os Estados da Federação.

Priorizando o atendimento às famílias com uma renda per capita de até meio salário mínimo, ou seja, que vivem em situação de extrema pobreza, o Peti oferece uma compensação financeira para a retirada das crianças do trabalho, uma bolsa no valor de $\mathrm{R} \$ 25,00$ por criança nas áreas rurais e de $\mathrm{R} \$ 40,00$ nas áreas urbanas, ou, mais precisamente, nos municípios com uma população igual ou superior a 250 mil habitantes, condicionada a uma freqüência regular à escola, assim como à "Jornada Ampliada" no turno complementar.

Os municípios são responsáveis pela implementação da Jornada, recebem do governo federal R\$ 20,00 por criança ou adolescente para a sua manutenção, ${ }^{1}$ devendo contratar monitores qualificados, propiciar espaços e materiais necessários para seu bom funcionamento. Além de almoço e merenda reforçados, a Jornada deve propiciar reforço escolar, atividades culturais, esportivas e de lazer às crianças atendidas, contribuindo para a melhoria do seu desempenho escolar, a ampliação dos seus horizontes e o desenvolvimento das suas potencialidades.

A expansão do Peti em 2000 foi acompanhada por algumas redefinições, como a perda do seu caráter preventivo e o estabelecimento de "metas" para os diversos Estados, que por sua vez as redistribuem entre os municípios; o programa se estendeu a áreas urbanas e metropolitanas e passou a contemplar um maior elenco de atividades que envolvem o trabalho precoce, como os lixões, o comércio ambulante e em feiras livres, o cultivo de algodão, fumo, café e laranja, a ocupação em cerâmicas e olarias ou em garimpos e pedreiras, entre outras; foi estabelecido um tempo máximo de quatro anos para a permanência dos beneficiários e, para justificá-lo, a Secretaria de Estado de Assistência Social - Seas, do Ministério da Previdência e Assistência Social, a quem o Peti se encontrava vinculado, ampliou seus objetivos e responsabilidades.

Essa ampliação considerou sobretudo a centralidade da família, que, de acordo com as novas orientações,

[...] deve ser trabalhada por meio de ações socioeducativas e de geração de trabalho e renda que contribuam para o processo de emancipação, para sua promoção e inclusão social, tornando-as protagonistas do seu próprio desenvolvimento social (PETI, 2002).

Para tanto, as famílias assistidas pelo Peti passaram a ter um acesso prioritário ao Programa Nacional de Geração de Emprego e Renda em Áreas de Pobreza - Pronager, desenvolvido pelo Ministério do Interior na ocasião. De acordo com o Manual de Orientações do Peti, publicado em 2002,

O Pronager é um programa que visa gerar ocupação e renda para os chamados 'excluidos' sociais, potencializando todos os recursos e vocações econômicas da comunidade.

O Pronager parte da capacitação de pessoas desempregadas ou subempregadas, para sua organização em empresas, associações e cooperativas de bens elou serviços com competitividade no mercado (PETI, 2002, p. 14).

Com uma metodologia que viabilizaria uma capacitação rápida e massiva, acessível a pessoas com baixa escolaridade e qualificação, o Pronager propiciaria a inserção de uma imensa parcela de excluídos dos mecanismos comuns de formação profissional, crédito, produção e consumo, contribuindo para a superação da pobreza e para a redução das desigualdades sociais.

Sem maiores considerações sobre a validade dessas expectativas, elas ficaram longe de se concretizar. A mobilização e a capacitação das famílias iniciadas pelo Pronager em algumas áreas não foram seguidas pelo apoio indispensável aos pequenos empreendimentos que ele procurou estimular (ou seja, por assistência técnica, microcrédito e outras condições). Reconhecendo a insuficiência da sua estratégia, a própria Seas passou a estimular os Estados a buscarem alternativas para a melhoria das condições das famílias assistidas pelo Peti, disponibilizando alguns recursos para esse fim. Ao que se sabe, porém, tal iniciativa foi implementada apenas na região sisaleira do Estado da Bahia, com o Programa Prosperar.

No quadro de instauração do novo governo federal, a partir de 2003, tanto os rumos quanto a própria persistência do Peti tornaram-se indefinidos. Em 2003, o programa foi mantido, na expectativa de uma avaliação, e em 2004, com a unificação dos programas federais de transferência de renda (como o Bolsa-Escola, o Vale-Gás ou o Cartão Alimentação), sua incorporação ao Bolsa-Família foi cogitada, mas não chegou a se realizar, pelos seus objetivos e especificidades. Em fevereiro de 2004, porém, foi anunciado pela imprensa um corte de $80 \%$ das verbas do Peti no orçamento de 2004 e a transferência das mesmas para o 
Bolsa-Família. Com a repercussão negativa dessa decisão e as pressões da rede de solidariedade à infância e à adolescência (que inclui órgãos como o Unicef e a OIT), no dia seguinte essa decisão teria sido revertida, garantindose a continuidade do atendimento em 2004 (FOLHA DE S.PAULO, 12/02/2004, p. A3). Mas o repasse de verbas federais para os municípios permaneceu atrasado e mais uma vez, segundo a imprensa, os recursos destinados à Jornada Ampliada seriam reduzidos em $45 \%$, sendo suficientes para custeá-la apenas até junho de 2004, se não houvesse uma suplementação (FOLHA DE S.PAULO, 13/03/2004, p. A3).

Não se dispõe, ainda, de uma avaliação mais ampla e sistemática das condições de funcionamento e do impacto do programa no conjunto de municípios onde ele foi implantado. ${ }^{2}$ Contudo, a partir de uma auditoria efetuada em 2000 pelo Tribunal de Contas da União, de alguns estudos parciais e da própria observação direta dos seus responsáveis, pode-se constatar que o Peti apresenta problemas, efeitos positivos e desafios. Entre os primeiros estão uma cobertura insuficiente das crianças que exercem atividades laborais; atrasos recorrentes no repasse de verbas e no pagamento das bolsas; ${ }^{3}$ insuficiência do apoio e da contrapartida das prefeituras para a implantação da Jornada; ausência de critérios, falta de fiscalização, interferência política e clientelista na escolha das crianças contempladas; carência de maior controle sobre as verbas repassadas aos governos locais; desarticulação entre a escola regular e a Jornada; funcionamento da mesma em condições inadequadas; baixa qualificação dos monitores, cuja capacitação é bastante variada entre os municípios.

No que se refere aos benefícios, destacam-se a contribuição do programa para a melhoria das condições de nutrição e do desempenho escolar de crianças e adolescentes (além da sua retirada do trabalho), reduzindo a repetência e a evasão, além do impacto positivo da transferência de recursos para a economia e o comércio dos municípios. Têm sido qualificados como desafios a continuidade da assistência, o destino dos egressos e principalmente a geração de trabalho e renda para as famílias contempladas.

Algumas dessas questões foram aprofundadas, podendo ser retomadas a partir da experiência do Peti no Estado da Bahia, especialmente na região sisaleira, que vem sendo acompanhada, atrai atenções como uma referência nacional e deu origem a estudos como os de Ramos e Nascimento (2001), Souza e Souza (2003), Carvalho e Maia (2003) e Fundação Abrinq (2002).

Em compensação, não se pode esquecer que este é um dos programas mais importantes da chamada rede de proteção social construída pelo governo federal na década de
90, com uma nova perspectiva de tratamento da questão social no Brasil. Assim, também contribui para a discussão dos impactos e significados dessa perspectiva, que, conforme assinalado em trabalhos anteriores (CARVALHO, 2001; CARVALHO; ALMEIDA, 2003), envolve uma concepção antinômica entre o desenvolvimento econômico e o social, considerando o segundo como um subproduto do primeiro; despolitiza a questão social, dissociando-a da injustiça e da desigualdade e subordinando o desenvolvimento e as políticas sociais aos ditames absolutos da economia, reduz a questão social ao problema da pobreza, com uma outra compreensão deste fenômeno; adota uma concepção residual que questiona o caráter universal das políticas sociais, direcionando-as, fundamentalmente, aos contingentes excluídos do mercado e em situação de maior pobreza, com o objetivo de atenuar os seus efeitos mais perversos e o seu potencial conflituoso e disruptivo e promove uma reconfiguração do sistema de proteção e das políticas sociais, adequando-os a essas orientações.

Com uma disponibilidade reduzida de recursos e sujeita a pressões crescentes pela sua contenção, a chamada "área social" do Estado brasileiro vem buscando uma racionalização dos gastos e uma adequação das suas ações às orientações acima mencionadas, por meio da focalização (direcionando-as para os segmentos considerados mais vulneráveis, como crianças, adolescentes e produtores rurais de baixa renda), da descentralização e da busca de novas parcerias com o mercado e a sociedade. Reproduzindo uma concepção da vida social fragmentada, os “problemas sociais" passaram a ser enfrentados pela multiplicação de políticas e programas sociais, emergenciais e isolados, sem um projeto que os articule e lhes imprima um sentido político (COHN, 1999). Além disso, esses programas são implantados à margem do institucionalismo vigente, têm um caráter flexível e não se constituem em direitos, como assinala Ivo (2001), estando sujeitos a uma grande instabilidade ou a uma fácil extinção.

\section{O PETI NO ESTADO DA BAHIA}

Na Bahia, o Peti foi implementado inicialmente na região sisaleira, marcada não apenas pela intensidade do atraso, da pobreza e da utilização da mão-de-obra infantil em condições especialmente intoleráveis, como também por uma forte mobilização do associativismo, constituídos, conforme Ramos e Nascimento, em torno de três elementos básicos: as Comunidades Eclesiais de Base - CEBs, os 
sindicatos rurais liderados pela Contag e as organizações estimuladas pelo Movimento de Organização Comunitária - MOC, organização não-governamental com tradição e experiência de mais de 30 anos de atuação em prol das famílias carentes da zona rural e das periferias urbanas.

$\mathrm{Na}$ região sisaleira, as condições de trabalho e a utilização da mão-de-obra infantil já chamavam a atenção desde a década de 70 , quando foi organizada uma ampla campanha alertando as autoridades competentes para o problema das mutilações pelas máquinas de beneficiamento do sisal e reivindicando tanto medidas para evitálas como a aposentadoria por invalidez para os trabalhadores mutilados. Além disso, na década de 90 a região também se destacou pela implementação de algumas experiências contra a utilização de crianças como mãode-obra. Uma delas foi um projeto de caprinocultura denominado Bode Escola, desenvolvido pelos sindicatos de trabalhadores rurais em conjunto com o MOC e com o apoio da OIT.

Para a implementação do Peti na Bahia, em 1996, foi criada a Comissão Interinstitucional de Prevenção e Erradicação do Trabalho Infantil, vinculada à Secretaria do Trabalho e Ação Social do Estado da Bahia - Setras; no início com um caráter marcadamente oficial. Contudo, com o apoio do Fórum Nacional e do escritório local do Unicef e a sustentação de uma forte rede de entidades de defesa dos direitos das crianças e dos adolescentes e de uma sociedade local bastante ativa, desenvolveram-se articulações, pressões, debates e negociações que contribuíram para dar ao programa uma feição diferenciada (RAMOS; NASCIMENTO, 2001).

Com uma expressiva participação da sociedade civil, a comissão estadual assumiu um caráter deliberativo, único entre os Estados brasileiros, e definiu critérios para a prioridade de atendimento aos municípios. Foi estabelecida uma parceria entre a Setras, o Unicef, o MOC e a Universidade Federal da Bahia - UFBA (que se mantém até o presente) e, para evitar uma utilização clientelista e eleitoreira do programa e assegurar uma melhor condução, foram tomadas providências que envolveram:

- uma ampla participação da sociedade organizada no seu desenvolvimento;

- a criação de mecanismos que viabilizassem uma administração compartilhada entre instituições governamentais e não-governamentais, que terminou se consolidando por meio de grupos gestores municipais;

- o cadastramento das famílias e crianças pelo Centro de Recursos Humanos da Universidade Federal da Bahia, que assegurasse não apenas uma maior isenção na identificação e escolha dos beneficiários, como também análises sobre a realidade de cada município;

- uma construção compartilhada e evolutiva do programa e, particularmente, da metodologia da Jornada Ampliada, com pesados investimentos na capacitação e seleção dos monitores. Essa seleção é realizada através de prova escrita e de uma entrevista feita pela equipe técnica da Setras.

Nesse processo, o governo estadual foi sensibilizado com a importância do programa e a participação da sociedade na sua condução. Se nas demais Unidades da Federação a contribuição estadual é periférica, na Bahia o governo tem assumido um papel crucial no financiamento e na condução do programa, por meio da Setras, cuja equipe é responsável pelo acompanhamento. Além do custeio do processo de seleção das crianças beneficiadas, recursos orçamentários expressivos têm sido destinados à capacitação e ao pagamento dos monitores no conjunto de municípios, contribuindo tanto para a unidade da proposta pedagógica como para uma melhoria da qualidade da Jornada Ampliada.

A parceria entre a Setras, o Unicef e o MOC levou à implementação de um Programa de Educação Complementar do Peti, criado e executado pelo MOC na região sisaleira, com financiamento do Unicef e o envolvimento e a supervisão da comissão estadual. Esse programa viabilizou uma capacitação sistemática dos monitores, que desenvolvem uma prática pedagógica mais qualificada, uma consciência do valor social do seu trabalho e do seu papel como agente de transformação social. Permitiu, ainda, o acompanhamento dessa prática, em reuniões mensais com os coordenadores da Jornada Ampliada nos diversos municípios e inovações como o Projeto Agente da Família e o Baú de Leitura (SOUZA; SOUZA, 2003).

Os agentes de família são representantes das comunidades que recebem uma pequena ajuda de custo para fazer contatos e reuniões com as famílias inseridas no programa, incentivando a sua participação. Já o Baú de Leitura tem como objetivo incentivar a leitura prazerosa e crítica nas escolas públicas rurais e nas Jornadas Ampliadas, beneficiando crianças e adolescentes cujas privações também se expressam pela falta de acesso à cultura e à informação. Para tanto, o projeto viabiliza a circulação de um baú com vários livros infanto-juvenis entre as escolas (em regime de revezamento) e capacita professores e monitores para o desenvolvimento da prática da leitura e da sua utilização em jogos, encenações teatrais e outras atividades lúdicas, desenvolvendo a capacidade de leitura e escrita, a compreen- 
são e a imaginação de meninos e meninas do Peti. ${ }^{4}$ Além disso, quando a necessidade de geração de renda para as famílias e as limitações do Pronager tornaram-se patentes, foi a partir da experiência e do compromisso do MOC que teve origem o chamado Projeto Prosperar, que vem atingindo cerca de 5 mil famílias do Peti com ações de capacitação, crédito e uma continuada assistência técnica.

Da região sisaleira o Peti se estendeu a outras áreas, fazendo-se presente em 93 municípios em 14 das 15 regiões do Estado da Bahia, alargando o leque de atividades contempladas e retirando 117.809 crianças e adolescentes do trabalho, não apenas no sisal e nas pedreiras como na cafeicultura, na cacauicultura, nos lixões, no comércio ambulante, na coleta de sucata ou na mariscagem.

Como já foi mencionado, porém, essa extensão foi acompanhada pela perda do caráter preventivo e por uma grande restrição na cobertura do programa, com o estabelecimento de um sistema de "metas" para cada município, que representa uma "focalização da focalização". Salvador, por exemplo, a terceira maior capital brasileira, com uma grande incidência do trabalho precoce, muitas vezes em condições especialmente penosas e degradantes, recebeu de início uma "meta" de apenas 5 mil bolsas, exigindo procedimentos cada vez mais rigorosos e refinados para a seleção dos beneficiários. ${ }^{5}$

O cadastramento realizado pela UFBA deixa bem claro o perfil desses beneficiários, que são crianças e jovens que pertencem a famílias extremamente empobrecidas de pequenos produtores rurais, muitas vezes obrigados a trabalhar de "ganho" em outras propriedades para assegurar a sua subsistência; de trabalhadores rurais que, expulsos das propriedades, transferiram-se para as periferias urbanas, na expectativa de encontrar serviço, ou que trabalham como diaristas em atividades agrícolas típicas de cada região; famílias de indivíduos que estão na base da pirâmide do mercado de trabalho urbano, como os trabalhadores menos qualificados da construção civil, as empregadas domésticas, os vendedores ambulantes, os catadores de material reciclável (latas de alumínio, principalmente) nas ruas e lixões da cidade, ou de desempregados, sem qualquer ocupação e renda.

O Peti se propõe a atender preferencialmente famílias excluídas, com uma renda per capita de até meio salário mínimo, com crianças e jovens precocemente ocupados. No caso da Bahia, porém, a pobreza das famílias assistidas chama a atenção, uma vez que $80,6 \%$ delas tinham uma renda per capita inferior a um quarto do salário mínimo e $14,9 \%$ entre um quarto e menos de meio salário. Entre os responsáveis por essas famílias (a mãe ou substituta, por definição do programa, com raras exceções), 69,3\% se declararam analfabetas ou apenas "alfabetizadas". Como nessa população a escolaridade tende a ser mais reduzida entre os homens, $81,1 \%$ dos pais encontravam-se nessa situação. Além disso, durante o cadastramento várias carências foram observadas nos domicílios, onde adultos e crianças muitas vezes dormiam em esteiras ou no chão batido e apresentavam claros sinais de desnutrição.

Por outro lado, o nível de mobilização e organização existente nos municípios onde o Peti começou a ser implantado (que viabilizou uma significativa participação da sociedade civil no acompanhamento e gestão do programa, a sensibilização de autoridades locais, negociações e compromissos básicos com os prefeitos) não é encontrado em outros municípios e regiões. E onde a mobilização é mais reduzida, a rede de associações apresenta-se mais frágil e as lideranças são menos ativas, o programa enfrenta dificuldades: os grupos gestores não conseguem se consolidar e nem sempre as elites políticas locais se sensibilizam com a questão do trabalho infantil, deixando de dar a contrapartida do município ou resistindo à participação e ao controle da sociedade, acostumados às velhas práticas patrimonialistas e clientelistas e à "cultura do favor" que permeiam os programas sociais no Brasil. Além disso, embora a Setras tenha tentado replicar a parceria com o MOC, articulando-se com organizações não-governamentais para melhorar as condições de funcionamento e o próprio alcance do programa em outras regiões, esses esforços geralmente não foram bem-sucedidos.

Assim, há municípios baianos onde a Jornada Ampliada tem uma estrutura bastante precária, encontra-se suspensa ou em alguns casos sequer foi iniciada e a própria freqüência escolar deixa de ser observada (inclusive por orientação dos prefeitos), possibilitando o retorno das crianças ao trabalho. Em outros locais, as mães ignoram o próprio nome do programa que retirou os seus filhos do trabalho (confundindo-o com o Bolsa-Escola), ${ }^{6}$ evidenciando como são frágeis os laços com as famílias, apesar da centralidade que lhes é atribuída no discurso oficial. Com exceção daqueles grupos atendidos pelos agentes de família, na região do sisal, esses laços se resumem à participação em algumas reuniões com os monitores, nas quais se discutem basicamente o desempenho e o comportamento dos filhos ou se desenvolvem algumas atividades lúdicas e comemorações como o Dia dos Pais ou Dia da Família.

Outros problemas observados, comuns a todo o Brasil, são a fragilidade e o despreparo das equipes técnicas lo- 
cais nas regiões mais pobres e atrasadas, que prejudicam o seu papel de protagonistas nos programas sociais; os freqüentes atrasos na liberação dos recursos da União para esses programas, algumas vezes resultantes de dívidas com o INSS, cujo parcelamento precisa ser negociado; a dissociação entre o ensino regular e a Jornada Ampliada e, principalmente, a extrema precariedade da escola pública a que têm acesso os filhos das classes populares.

Estudos como os de Neves (1999) ou Azevedo, Menezes e Fernandes (2000), entre vários outros, têm constatado que o trabalho precoce geralmente não chega a impedir a freqüência à escola, o que o cadastramento $\mathrm{e}$ os estudos do Peti na Bahia também comprovaram. Contudo, ele está associado à repetência, à defasagem idade/ série e a um atraso cumulativo que levam ao abandono da escola com baixos níveis de escolaridade, não apenas pela condição de atividade das crianças mas pelas características e qualidade da escola. Embora valorizem a educação (até porque têm consciência dos efeitos perversos da sua carência), os pais não têm expectativa de que os filhos aprendam nessa escola, esperando, apenas, que ela thes forneça noções básicas de leitura e matemática. Para os estudantes ela também não é atrativa, desestimulando a dedicação, o rendimento e a permanência.

Como seria de esperar, ao longo dos levantamentos de campo efetuados pela UFBA, principalmente na zona rural, as escolas visitadas funcionavam sem infra-estrutura adequada, com professores pouco qualificados e dispondo apenas de um quadro-negro como material. Algumas se resumiam a pequenas salas, multisseriadas, nas quais a cópia constituía a atividade básica. Por isso mesmo, não chega a ser surpreendente que, em um dos municípios pesquisados, ao saber dos objetivos e condições de funcionamento do Peti um garoto de 13 anos pediu:

“Ah, não coloque meu nome aí não, Deus me livre; se já não agüento ficar um tempo na escola, imagine o dia todo...".

\section{EFEITOS E LIÇÕES DO PETI}

Nessas circunstâncias, qual o significado e os efeitos do Peti sobre os seus beneficiários? Quais as suas limitações? Que elementos ele oferece para uma análise mais ampla do novo paradigma brasileiro de políticas sociais?

Pesquisas de campo realizadas pelo $\mathrm{CRH}$ durante o cadastramento e, mais recentemente, em alguns municípios do recôncavo baiano, ${ }^{7}$ onde o programa começou em
2000, assim como avaliações efetuadas pela Fundação Abrinq (2002) e por Souza e Souza (2003) na região sisaleira permitem algumas conclusões.

As primeiras se reportam à própria relevância dos objetivos do programa e não há dúvidas de que combater o trabalho precoce (ainda que apenas nas suas piores formas), resgatando a dignidade e a infância e adolescência, é essencial. O depoimento de uma mãe cujos filhos trabalhavam no lixão deixa isso muito claro, assinalando que:

Hoje [os filhos] não perdem mais aula, só se preocupam em estudar. Hoje eles andam como seres humanos, se vestem direitinho, cuidam da saúde. Antes não tinha banho que tirasse o mau cheiro; não andam com pé cortado, feridentos, com crecas [sic]. Andam com a pele limpinha. Tinha muita discriminação com meus filhos, porque andavam no lixo, hoje não tem mais isso, [os outros] diziam que comia lixo, chamavam eles de fedorentos (SOUZA; SOUZA, 2003).

O número de crianças e jovens retirados do trabalho é expressivo na Bahia e no Brasil, mas está muito aquém das necessidades, deixando de fora um grande número de beneficiários potenciais. A pesquisa realizada pelo $\mathrm{CRH}$ deixou muito evidente esse fato, com mudanças na metodologia do cadastramento e a definição de critérios cada vez mais refinados para escolher entre as famílias em situação de extrema pobreza, com crianças em ocupações adversas, aquelas em pior situação.

Com esse grau de pobreza, a transferência de renda propiciada pelo Peti torna-se fundamental para a reprodução social dessas famílias. Utilizados basicamente para a compra de alimentos, os recursos da bolsa também viabilizam a aquisição de material escolar, roupas e calçados para as crianças, a compra de remédios ou o pagamento eventual de contas de água e de luz, conforme depoimentos das famílias entrevistadas:

“Ajuda na alimentação, compra roupa... quando recebo é só para pagar quem eu devo. Esse dinheiro é uma bênção, é pouco, mas serve".

“Ah! Eu compro tudo para as crianças. Eu tenho sete filhos na escola. Em primeiro lugar, a alimentação da família [que] é feijão, farinha e carne. Mas a carne hoje, para nós, é um esporte. Lá de vez em quando.”.

"[O dinheiro da bolsa é gasto com... 'Comida'] O dia que recebo é o dia mais alegre da vida, porque compro comida".

"[...] agora estou apertada, recebi $R \$ 100$, fui na rua, paguei $R \$ 25$ de luz (que estava atrasada) e fiz uma comprinha de comida" (SOUZA; SOUZA, 2003, p. 39). 
Algumas vezes esse dinheiro também viabiliza a aquisição de móveis básicos (uma mesa com cadeiras, camas ou colchões), eletrodomésticos ou pequenas melhorias na habitação, sobretudo quando a família tem vários filhos no programa ou pagamentos atrasados e acumulados são liberados de uma só vez. Além disso, nos municípios do recôncavo observou-se que as famílias do Peti que recebem mensalmente pelo Cartão Social da Caixa Econômica adquirem crédito junto ao comércio local, podendo fazer compras à prestação.

Contudo, a preocupação básica é com a subsistência imediata e isso interfere na própria compreensão do programa. No decorrer da pesquisa de campo observou-se que uma parte das famílias possuía uma visão clara sobre os objetivos do Peti, declarando, por exemplo, que ele "veio para as crianças não trabalharem, para que as crianças fiquem na escola e na Jornada", ou que "é para as crianças não trabalharem fora, contra a exploração". A maior parte das mães entrevistadas, porém, considera o programa como algo muito bom que lhes foi oferecido em razão da sua pobreza e necessidades, afirmam que:

"É bom porque os meninos comem. Já teve uma reunião que falou sobre o programa, mas já esqueci."

"É um programa bom, ensina mais às crianças, ajuda muito na alimentação, dá dinheiro para comprar roupa e calçado para eles."

"É um programa que ajuda pessoas carentes; muitos precisam de dinheiro, mata a fome de muitas crianças."

"É tudo, porque [as crianças] aprendem muito. O Peti ensina o dever que eu não sei ensinar; lá tem alimentação $e$ dinheiro para comprar comida, pagar o gás, o dinheiro ajuda muito."

"Foi uma ajuda muito grande do governo, que veio para nós” (SOUZA; SOUZA, 2003).

Declarações como esta última confirmam que a noção de direitos não está incorporada ao universo da maioria das famílias assistidas pelo Peti, conforme ressaltado por Souza e Souza (2003, p. 34) a partir da pesquisa na região sisaleira e de declarações como esta: "Ouvimos falar de direitos. Mas pobre não tem direitos. Pobre é pobre". Como na área do sisal, nos municípios do recôncavo também predomina uma visão de "ajuda" para as famílias "fracas", que não têm como sobreviver, representando uma "bondade" do governo ou uma "bên- ção" de Deus. ${ }^{8}$ Com essa perspectiva, diversas mães explicaram o ingresso dos seus filhos no programa "[...] porque foi uma sorte dada por Deus, era uma família que merecia", "porque a gente era muito fraco", ou, ainda, "[...] eu não entendo nada, eu acho assim, que foi uma sorte que deram a eles".

Além da transferência direta de renda, a freqüência à Jornada Ampliada tem propiciado uma melhoria do padrão nutricional e de saúde das crianças, a aquisição de noções e hábitos de higiene e mudanças de comportamento como redução da agressividade e da inibição e maior facilidade de expressão e de convívio social, notadamente nas Jornadas que incentivam trabalhos em grupo e enfatizam o desenvolvimento de atividades lúdicas e culturais. Verifica-se, também, o crescimento do interesse pelo estudo e pela aprendizagem, uma melhoria do desempenho com o reforço escolar e, pelo menos para uma parte dos beneficiários, uma ampliação de horizontes.

Por isso mesmo, no contato com as famílias os pais também ressaltaram a importância e os efeitos positivos do programa em termos da alimentação, do reforço escolar (com grandes elogios à dedicação e ao trabalho dos monitores), do acesso a atividades lúdicas, culturais e esportivas, do desenvolvimento pessoal e da própria guarda dos filhos. Com a freqüência à Jornada, além de um maior interesse pelos estudos e um melhor desempenho escolar, as crianças teriam ficado "mais responsáveis", "mais espertas", "mais sabidas" e mais "desasnadas" (desembaraçadas). Conforme depoimentos das mães,

"[Eles] aprenderam a falar direitinho, ler, escrever, desenhar, brincadeiras diferentes. Na escola ajudou, nunca perderam de ano, não fazem recuperação, passam direto."

"[...] melhorou na educação, no tratamento dos pais, no comportamento, aprendeu muitas coisas."

“Tem mais amigos, desenvolveu no conhecimento."

"Hoje lê melhor, traz livros para casa, com o Baú de Leitura."

"Os monitores se interessam pelos meninos, fazem o dever de casa que a gente não sabe ensinar, os meninos também se divertem."

"[A Jornada] é boa porque aprende várias coisas e [ele] não fica na rua, aprendendo coisas ruins" (SOUZA; SOUZA, 2003). 
Depoimentos dos meninos e meninas tendem a confirmar essas declarações. Estimulados a se pronunciar sobre os efeitos e benefícios do programa, alguns não souberam responder ou não manifestaram um maior entusiasmo, considerando que na sua vida continuava "tudo igual". Outros se reportaram à saída do trabalho, à contribuição da bolsa para o sustento da família ou à alimentação recebida na Jornada. A maioria do grupo estudado, porém, refletindo o resgate da sua infância e adolescência, ressaltou o acesso a atividades lúdicas, esportivas e culturais, uma melhor aprendizagem e mudanças como:

"Não sabia matemática, aprendi no Peti."

"Na Jornada a gente estuda, faz teatro, conhece mais gente, aprende bastante. Lá não me bato para fazer o dever, elas [as monitoras] ensinam."

"Estou aprendendo mais, a ler e a escrever melhor, passei a me interessar mais pelos estudos, os professores [da Jornada] incentivam."

"Deixei de trabalhar, o Peti tem muitas coisas importantes, ensinam o que as pessoas têm dificuldade e tem brincadeira também."

"Fiquei gostando de assistir ao noticiário [pela televisão] porque uma monitora pediu aos alunos para assistirem, para fazer um trabalho escolar sobre a guerra do Iraque." (SOUZA; SOUZA, 2003).

Benefícios dessa ordem também foram constatados nos estudos efetuados na região sisaleira pela Fundação Abrinq (2002) e por Souza e Souza (2003). Fazendo uma análise bastante ampla e aprofundada das condições e transformações ocorridas com os beneficiários do Peti naquela região, estes últimos autores também ressaltam que, com o reforço escolar, uma maior exposição a debates e a utilização do Baú de Leitura, nas provas da Saeb, cujos resultados foram divulgados em 2002, os alunos envolvidos com o Peti obtiveram um desempenho superior ao encontrado no Nordeste. ${ }^{9}$

É claro que esses resultados não podem ser generalizados, uma vez que, com o Programa Complementar MOC/ Unicef e outras condições assinaladas, a trajetória do Peti na região sisaleira é bastante especial. Como já foi mencionado, mesmo no Estado da Bahia, onde o governo estadual, em parceria com o MOC e o Unicef, vem fazendo um amplo trabalho para uma melhor seleção, capacitação e acompanhamento dos monitores, unificando a proposta pedagógica e qualificando a Jornada, o programa apresenta significativas variações locais. No conjunto do país, onde sua condução depende de cada município, a diferenciação é ainda mais acentuada, reduzindo-o, algumas vezes, ao simples pagamento de bolsas. ${ }^{10}$

Ademais, os ganhos assinalados tendem a ser temporários e relativos, uma vez que as crianças normalmente apresentam significativo atraso escolar ao serem incorporadas ao programa (saindo dele, na maioria dos casos, sem concluir o ensino fundamental) e este está muito longe de mudar as condições de suas famílias.

Conforme avaliação da Fundação Abrinq (2002), na própria região sisaleira, após cinco anos, o Peti contribuíra para a redução do trabalho precoce, para a permanência das crianças na escola e para algumas melhorias em termos de nutrição, habitação, vestuário e saúde. No aspecto econômico, porém, não constava nenhuma mudança significativa na situação das famílias, que não se diferenciavam fundamentalmente daquelas não incorporadas ao programa e permaneciam abaixo da linha de pobreza, tal como normalmente definidas.

O estudo de Souza e Souza (2003) confirma essa constatação, assinalando como as famílias persistem em situação de penúria, sem terra, sem nenhuma poupança ou capacidade de tomar empréstimos, com mudanças que se restringem à melhoria da alimentação, a alguns consertos na moradia, à aquisição de alguns móveis, uma televisão ou alguns pequenos animais, assim como a uma transformação ou outra na compreensão do mundo, da educação e do trabalho, conforme avaliação das famílias entrevistadas:

"Com essa bolsa? Continuou tudo no mesmo" (SOUZA; SOUZA, 2003, p. 67).

"Só mudou um pouco porque, de qualquer maneira, esse que está lá no Peti não dá despesa dentro de casa. A comida que ele não come em casa já serve para o outro. Mas a situação financeira continua a mesma coisa, porque a gente demora muito para receber. E é muito pouco" (SOUZA; SOUZA, 2003, p. 69).

Não foi muito diferente o que se observou em municípios do recôncavo baiano, incluídos no programa para a retirada das crianças principalmente da produção clandestina de fogos de artifício, após uma grande explosão com várias vítimas fatais. As famílias continuam na pobreza (em certos casos, de forma degradante) e quando reconhecem algumas melhorias de vida isso se dá devido a sua extrema carência e no nível da sobrevivência imediata: ${ }^{11}$

"Com esse dinheiro já dá para comprar qualquer coisa; se não fosse o Peti eu não podia fazer nada, porque meu mari- 
do trabalha para ganhar $R \$ 7,00$ por dia [como trabalhador rural]."

"Melhorou no ensino das crianças, tem almoço e merenda, o pagamento [da bolsa] ajuda nas despesas."

"[Melhorou] sim, às vezes dá para ajudar na alimentação. A gente compra fiado e depois paga; os comerciantes vendem fiado pra gente que é do Peti; quando atrasa a gente explica pra eles, eles entendem."

"Foi uma coisa boa que o governo mandou. O dinheiro é uma coisa ótima. Foi o que me salvou."

"Minha valença é o Peti; se acabar não sei o que fazer; sou capaz de morrer." (SOUZA; SOUZA, 2003).

Esses e outros depoimentos deixam claro como se criou uma dependência e uma verdadeira neurose (denominada por Souza e Souza como "síndrome da perda da bolsa") nas famílias assistidas. Há, também, o problema do que fazer com os meninos e meninas desligados por ultrapassarem o limite de idade, que na ausência de outras alternativas e sem qualquer apoio tendem a deixar a escola, a procurar trabalho ou voltar às atividades penosas e precárias de onde foram retirados, muitas vezes com uma grande frustração.

Entre os egressos entrevistados no recôncavo baiano, por exemplo, um jovem agora com 18 anos passou três anos no Peti e, quando saiu, abandonou a escola e não pretende voltar a estudar. Casou-se, já tem dois filhos e vive em condições bastante precárias, com o auxílio da família e o que ganha como ajudante de pedreiro. Outra moça parou de estudar aos 15 anos, na sétima série; ficou grávida, teve um filho e mora com os pais e de vez em quando ganha algum dinheiro fazendo faxinas. Declarou que "na Jornada Ampliada aprendi algumas coisas, mas já esqueci". Um rapaz, atualmente com 16 anos, cursa a quinta série; ficou dois anos e meio no programa, onde aprendeu a ler melhor, mas "a vida não melhorou porque não acho trabalho”. O último exemplo é de um jovem de 18 anos, que participou do Peti e do Agente Jovem e hoje cursa a primeira série do segundo grau e faz biscates, cortando grama, esforçando-se para mudar de vida,

“[...] no ano passado fiz um curso de informática, com certificado. Mas a vida não melhorou porque estou sem emprego e somente a esperança de arranjar um”.

Para equacionar esse tipo de problema, foi criado o Programa Agente Jovem, direcionado a carentes entre 15 e 17 anos e dando prioridade aos egressos do Peti e de outros programas sociais. Oferecia uma bolsa no valor de $\mathrm{R} \$ 65,00$ aos seus participantes, condicionada à freqüência escolar e à sua capacitação e atuação na comunidade no apoio às áreas de saúde, meio ambiente e cidadania, articulada com sua participação em atividades de cultura, esporte e lazer. Mas o Agente Jovem teve uma cobertura insuficiente (incorporando apenas parte dos egressos do Peti), poucos resultados e uma curta duração. A necessidade de geração de trabalho e renda ficou cada vez mais patente, levando a Seas a ampliar os objetivos do Peti e a enfatizar a centralidade da família, além de articulá-lo ao Pronager.

Contudo, as novas orientações praticamente não saíram do plano do discurso. As ações e o próprio contato com a família continuaram muito restritos (com exceção da área sisaleira, onde existem os agentes de família) e os resultados do Pronager não apenas não foram propagados, como foi desativado em 2003. Em 2001, quando o insucesso do Pronager levou a Seas a incentivar os governos estaduais a buscarem alternativas, mais uma vez na região sisaleira e por meio de uma articulação entre a Setras e o MOC (aprovada e apoiada pela Seas), teve início o chamado Projeto Prosperar.

O Prosperar procura superar as limitações de experiências anteriores, que apostavam em um empreendedorismo popular sem qualquer apoio à sua sustentação. Contando com a infra-estrutura, a equipe técnica (composta por 20 profissionais, como sociólogos, agrônomos e técnicos em agropecuária) e uma experiência de mais de 30 anos do MOC em prol do associativismo, do cooperativismo e da melhoria das condições socioeconômicas das famílias pobres da região, esse projeto vem desenvolvendo um conjunto de ações integradas, que envolvem:

- o diagnóstico das condições socioeconômicas de uma parcela das comunidades e famílias assistidas pelo Peti nos municípios da área do sisal, selecionadas em conjunto com os grupos gestores locais;

- a formulação de um plano de desenvolvimento da comunidade, no qual as famílias são agrupadas de acordo com seus interesses produtivos;

- a capacitação dessas famílias, promovendo a racionalização do uso das suas propriedades (principalmente no que tange ao manejo de criatórios e técnicas de convivência com a seca), assim como a geração de novas ocupações produtivas para aqueles que não dispõem de terra;

- a concessão de crédito de baixo custo e longo prazo de pagamento, por meio de cooperativas rurais; 
- o acompanhamento dos projetos, com visitas periódicas (pelo menos duas por mês) dos técnicos e reuniões para assessoria às famílias;

- a avaliação do impacto do projeto, verificando a nova situação das famílias em termos de renda, emprego, alimentação, abastecimento de água, moradia, saneamento, posses e relações de gênero e geração.

Enfrentando o grave problema da má distribuição de terra e levando em conta tanto as condições e vocações da região quanto a viabilidade econômica dos empreendimentos, o Prosperar tem estimulado atividades como a caprinocultura (com a produção de embutidos e derivados), o artesanato de sisal, a apicultura, a produção de temperos, ovos e detergentes, beneficiando cerca de 5 mil famílias, em 30 municípios. A produção é destinada principalmente aos mercados locais, incluindo a própria Jornada Ampliada. Em alguns municípios, a prefeitura vem adquirindo alimentos para a Jornada junto às cooperativas do Prosperar, mantendo os recursos recebidos do governo federal no próprio município e ativando a produção local.

\section{OBSERVAÇÕES FINAIS}

A avaliação de impacto junto ao primeiro grupo de famílias (2.340) vinculado ao Prosperar ainda não foi efetuada. Contudo, apesar de obstáculos, como a estrutura agrária ou os reduzidos recursos à sua disposição, esse impacto pode ser diferenciado e mais positivo, na medida em que o programa vem associando capacitação e assistência técnica continuadas, acesso a microcréditos, estímulo à melhoria dos rebanhos e caprinocultura mais moderna, equacionando o problema da água ${ }^{12}$ e de acesso aos mercados. Ao demonstrar como é possível conviver com as condições ecológicas da área e trabalhar com pequenos produtores rurais, essa experiência também oferece subsídios para uma política nacional de desenvolvimento das condições sociais do semi-árido nordestino, demandadas há décadas.

Das evidências até aqui apresentadas podem ser tiradas algumas lições. No que se refere mais diretamente ao Peti, reafirma-se a importância do combate ao trabalho precoce, cuja face cruel o programa tornou mais evidente, desmistificando e combatendo, inclusive, a sua naturalização como "sina" das crianças pobres ou de seus supostos "efeitos educativos". Nessa perspectiva, a retirada de 810.769 crianças e adolescentes de ocupações especialmente penosas e degradantes, em 2.590 municípios brasileiros, viabilizando a sua permanência na escola e, através da Jornada, o seu acesso a atividades recreativas, esportivas e culturais, ampliando o seu capital cultural e os seus horizontes, não pode ser menosprezada. Mas podese questionar se políticas mais amplas e universais seriam mais eficazes, como um programa de renda mínima para as famílias, condicionado à freqüência de seus fillhos à escola e pesados investimentos para a melhoria da escola.

Como foi visto, mesmo focalizado nas "piores formas" de ocupação precoce (quando todas elas tendem a ser negativas), o Peti deixa de lado uma grande parcela da sua clientela potencial ${ }^{13}$ e não transforma significativamente as condições e perspectivas dos seus próprios beneficiários. Os ganhos obtidos quanto a nutrição, estímulos socioculturais e a própria escolarização tendem a ser relativamente restritos e temporários. Freqüentando uma escola pública de péssima qualidade (que não estimula a permanência e a dedicação) e trabalhando no turno complementar, ao ingressar no Peti os meninos e meninas apresentam um atraso escolar que poucas vezes pode ser compensado. Ainda que a Jornada funcione como uma "muleta" para essa escola, na expressão de Souza e Souza, ao atingir a idade limite para a permanência no programa a maioria não chega a concluir o ensino fundamental e após o desligamento, sem maiores perspectivas e tendo que contribuir para a subsistência da família, poucos continuam a estudar, persistindo com baixos níveis de escolaridade, restritas oportunidades ocupacionais e reproduzindo o ciclo de pobreza dos pais.

Aliviando essa pobreza, mas sem efeitos expressivos sobre a sua superação, o Peti também suscita reflexões mais amplas sobre o novo paradigma das políticas sociais, cujas características foram antes assinaladas. Isso porque, entre outros aspectos, a trajetória do programa coloca também em questão:

- a urgência de políticas governamentais (com pesados investimentos) orientadas para uma transformação e melhoria radicais do ensino público, implementando, inclusive, ainda que de forma progressiva, as disposições da Lei de Diretrizes e Bases sobre a escola em tempo integral;

- a importância da participação da sociedade civil no desenvolvimento e no controle das políticas sociais, assim como a própria fragilidade dessa participação;

- as potencialidades, os limites e as perversões da descentralização e da municipalização das políticas públicas e a necessidade da criação de mecanismos efetivos de subsídios e solidariedade entre os diversos níveis de governo, em um país tão heterogêneo como o Brasil, levan- 
do em conta as condições dos Estados e municípios com baixo nível de desenvolvimento econômico, político e institucional; e, sobretudo,

- os problemas e limites do paradigma mencionado.

Conforme assinalado em páginas anteriores, eles partem de uma concepção antinômica entre desenvolvimento econômico e desenvolvimento social, subordinando o segundo à dinâmica e às supostas exigências do primeiro. Enfatiza o combate à pobreza sem enfrentar seus determinantes estruturais (como a estrutura de propriedade da terra ou as desigualdades), com a multiplicação de um conjunto de programas setoriais, emergenciais, assistenciais e focalizados que, a exemplo do Peti, realizam pequenas transferências diretas de renda, com algumas condicionalidades. ${ }^{14}$

A experiência do Peti deixa patente como essas transferências são necessárias e relevantes, tendo em vista as condições de pobreza ou de indigência de uma grande parcela da população brasileira, apesar das suas limitações. Porém, não é com iniciativas dessa ordem que a perversa realidade social do país poderá ser transformada. Programas de alívio à pobreza (como os que compõe a chamada rede básica de proteção social) precisam ser associados a medidas que viabilizem a sua superação, mais precisamente, a políticas estruturais e amplas, que permitam a retomada do desenvolvimento com uma maior eqüidade social e que (mesmo quando de médio ou longo prazos) sejam orientadas, já no primeiro momento, para a eliminação do pauperismo e para o resgate da dignidade e dos direitos de cidadania de todos os brasileiros.

\section{NOTAS}

1. Na área urbana esse valor é de $\mathrm{R} \$ 10,00$ por criança ou adolescente nas capitais, regiões metropolitanas e municípios com mais de $250 \mathrm{mil}$ habitantes. Nos demais municípios o repasse é de $\mathrm{R} \$ 20,00$. Esses recursos só podem ser utilizados em material de consumo, ou seja, na compra de alimentos e materiais escolares, esportivos, artísticos e de lazer. Desde que não prejudique as ações essenciais da Jornada, 30\% do repasse pode ser gasto com os monitores, cuja seleção, capacitação e remuneração são de responsabilidade dos municípios (cf. Programa de Erradicação do Trabalho Infantil. Manual de Orientações. 2002). $\mathrm{Na}$ Bahia, porém, o governo estadual assumiu essas atribuições, garantindo a qualificação dos monitores e uma Jornada com uma concepção básica a ser trabalhada em todos os municípios, respeitadas as peculiaridades locais.

2. A Seas enviou aos municípios um questionário solicitando diversas informações sobre as condições locais de funcionamento do programa, que deu origem a um relatório preliminar, divulgado recentemente e de forma restrita, que não chegou a ser utilizado neste trabalho.

3. Conforme o relatório do Tribunal de Contas da União, atrasos no repasse de recursos do programa seriam freqüentes em $73 \%$ dos municípios do Norte, $81 \%$ do Nordeste, $43 \%$ do Centro-Oeste, $68 \%$ do Su- deste, $56 \%$ do Sul e $68 \%$ do Brasil. Com a implantação do Cadastro Único, algumas famílias do Peti passaram a receber a bolsa pontualmente, com o cartão da Caixa Econômica Federal, enquanto outras amargam as conseqüências dos atrasos. Curiosamente, há famílias em que um dos filhos recebe pelo cartão e outros pela prefeitura, com um grande atraso.

4. Inicialmente restrito à região do sisal, o projeto do Baú de Leitura chamou a atenção de outros municípios, levando o Unicef a capacitar professores e monitores para a sua implementação, desde que as prefeituras se responsabilizassem pela aquisição e circulação dos livros.

5. Para a concessão das bolsas, nos primeiros municípios onde o Peti foi implantado (ou seja, na região sisaleira), a equipe coordenada pelo Centro de Recursos Humanos da UFBA realizou um censo de crianças e adolescentes ocupados ou em risco de trabalhar em atividades como a produção de sisal e as pedreiras. Com a perda do caráter preventivo e a concessão de bolsas sempre em um número muito inferior ao necessário, essa estratégia teve que ser modificada. Através de uma ampla reunião com representantes de entidades oficiais e de organizações da sociedade civil, em cada município passaram a ser identificados os locais onde se concentrava a ocupação precoce com caráter especialmente penoso, perigoso ou degradante. Nesses locais, foram identificadas e cadastradas famílias e crianças nessa situação. A partir das informações obtidas e da aplicação de alguns critérios, foram selecionadas aquelas em situação mais crítica para o ingresso no Peti (RAMOS; NASCIMENTO, 2001; CARVALHO; MAIA, 2003).

6. Como este artigo está centrado na análise do Programa de Erradicação do Trabalho Infantil, ele não se reporta a outros problemas da chamada rede de proteção social implantada nos anos 90, como a superposição de clientelas e benefícios ou a tentativa de implantação de um Cadastro Único dos beneficiários dos diversos programas, sob a responsabilidade da Caixa Econômica Federal.

7. Coordenada por Lúcia Pedreira e com participação de Sylvia Maia e da autora (cuja freqüência às reuniões da comissão estadual como representante da UFBA tem lhe propiciado valiosas informações), a pesquisa no recôncavo foi realizada entre fevereiro e abril de 2004 .

8. Conforme Souza e Souza (2003), apenas as famílias atendidas pelo agente de família na região sisaleira tinham uma postura mais crítica e reivindicatória.

9. Realizado por uma equipe interdisciplinar que incluiu educadores e psicólogos e ouviu depoimentos de famílias, crianças, monitores, grupos gestores, autoridades e empresários locais, o livro de Souza e Souza (2003) apresenta observações muito interessantes sobre o funcionamento e os efeitos do Peti na área sisaleira, inclusive do ponto de vista sociocultural. Entre os benefícios ali constatados estão o alívio que a Jornada representou para as mães, reduzindo a sua "lida" com a casa e os filhos e livrando-as do "vexame" de não poder ajudá-los nos deveres, assim como estímulos à economia e ao comércio local. Sem abordar todos esses aspectos, o presente artigo concentra suas análises sobre o impacto mais direto sobre as condições das famílias e crianças beneficiadas.

10. Até mesmo no Estado da Bahia há municípios que não chegam sequer a implantar todas as Jornadas. A qualificação dos monitores também vem sendo questionada nos demais Estados. Relatório do Programa de Capacitação de Monitores e Educadores de Apoio das Escolas Rurais da Jornada Ampliada, mencionado pela Coordenadora da Comissão Estadual de Pernambuco, por exemplo, ressalta que os mesmos "apresentam pouca escolaridade e que exercem profissões e ofícios tão distantes do universo do educador: cabeleireira, costureira, padeiro, etc." (BEZERRA, 2000, p. 84).

11. Melhorias um pouco mais substanciais foram assinaladas por apenas duas famílias. A responsável por uma delas, empregada doméstica, comprou um pequeno terreno na periferia do município, onde depois a patroa a ajudou a construir uma casinha; a outra família, que possui um pequeno pedaço de terra e cujo chefe trabalha como pedreiro, adquiriu uma vaca. Mas a situação dessa família não sofreu uma grande mudança e ela continua envolvida na perigosa fabricação de fogos de artifício (bombas) na própria residência. 
12. A convivência com as condições ecológicas do semi-árido baiano foi discutida na própria Jornada Ampliada da região sisaleira, com a realização de uma pesquisa sobre a questão da água na qual foram aplicados questionários em 38 mil domicílios e realizadas entrevistas com autoridades e lideranças locais. A partir dos dados dessa pesquisa foram trabalhados conteúdos de português e matemática e os meninos e meninas puderam analisar um dos problemas mais cruciais da região.

13. Até pela relatividade da definição, não há como estimar o número de envolvidos nas "piores formas" de trabalho infantil. Em termos mais gerais, embora a ocupação precoce venha se reduzindo de forma continuada e significativa em todo o Brasil, o total de crianças e adolescentes entre 5 e 17 anos ocupados em 2001 chegava a 5,5 mil, conforme informações da PNAD; $81 \%$ da mão-de-obra infantil começou a trabalhar antes dos 14 anos, e entre as crianças na faixa dos 5 aos 9 anos, 297 mil já se encontravam ocupados (IBGE, 2002).

$\mathrm{Na}$ Bahia, a comissão estadual não tem conseguido atender a vários municípios e a demandas do Ministério Público e da Delegacia Regional do Trabalho, pela insuficiência de metas. Entre as próprias famílias vinculadas ao programa algumas crianças são inseridas e outras não, criando situações como a observada em um dos domicílios do recôncavo baiano: enquanto uma das crianças ajudava os pais no fabrico de fogos de artifício, uma segunda assistia o programa de televisão, pois, como beneficiária do Peti, não podia trabalhar.

14. Como se sabe, nos primeiros meses de 2004 houve uma unificação de programas (como o Bolsa-Escola, Cartão Alimentação, Vale-Refeição, Vale-Gás e Fome Zero), através do Bolsa-Família. Isso introduziu uma maior racionalidade no sistema, atacando problemas como a superposição de beneficiários e clientelas, mas sem mudar suas orientações e seu significado.

\section{REFERÊNCIAS BIBLIOGRÁFICAS}

ARIÉS, P. História Social da Criança e da Família. Rio de Janeiro: Zahar, 1978.

ARREGUI, C.O. (Org.). Erradicação do trabalho infantil. Dimensionando as experiências de Pernambuco, Mato Grosso do Sul e Bahia. São Paulo: Evoé, 2000. 127p.

AZEVEDO, J.S.G. de; MENEZES, W.F.; FERNANDES, C.M. Fora de lugar. Crianças e Adolescentes no Mercado de Trabalho. São Paulo: Abet, 2000. 205p.

BEZERRA, M.A.P. Informe da Comissão Estadual de Erradicação do Trabalho Infantil em Pernambuco. In: ARREGUI, C.O. (Org.). Erradicação do trabalho infantil. Dimensionando as experiências de Pernambuco, Mato Grosso do Sul e Bahia. São Paulo: Evoé, 2000. p.79-90.

CAMPOS, M.S. et al. Desafio a Sociedade. Avaliação do Programa de Erradicação do Trabalho Infantil no Período 1996-97. São Paulo: IEE/PUC-SP; Brasília: Secretaria de Estado da Assistência Social/ MPAS, 1998. 160p.

CARVALHO, I.M.M. de.; ALMEIDA, P.H. Família e Proteção Social. São Paulo em Perspectiva, São Paulo, Fundação Seade, v. 17, n. 2, p. 109-122, abr./jun. 2003.

CARVALHO, I.M.M. de. Algumas considerações finais. In: CARVALHO, I.M.M. de.; MAIA, S.M. dos R. (Org.). Programa de Erradicação do Trabalho Infantil - Peti. Trajetória e beneficiários no Estado da Bahia. Salvador: Setras/CRH, 2003. p. 373-390.

Brasil: Reestruturação Produtiva e Condições Sociais. Caderno CRH, Salvador, n. 35, p. 123-149, 2001.

Direitos legais e direitos efetivos. Crianças, adolescentes e cidadania. Revista Brasileira de Ciências Sociais, São Paulo, Anpocs, v. 29, p. 127-142, 1995.
CARVAlHO, I.M.M. de.; MAIA, S.M. dos R. (Org.). Programa de Erradicação do Trabalho Infantil - Peti. Trajetória e beneficiários no Estado da Bahia. Salvador: Setras/CRH, 2003. 395p.

COHN, A. As políticas sociais no governo FHC. Tempo Social. Revista de Sociologia da USP, São Paulo, v. 11, n. 2, p. 183-197, 1999.

COSTA, A.C.G. da. O direito da infância e da juventude no Brasil. 10 anos do Estatuto da Criança e do Adolescente. Avaliando conquistas e projetando metas. Unicef, 1999.

DIEESE. A situação do trabalho no Brasil. São Paulo: 2001.

FOLHA DE S. PAULO, São Paulo, 13 fev. 2004, p. A3.

São Paulo, 12 fev. 2004, p. A3.

São Paulo, 11 fev. 2004, p. A4.

FUNDAÇÃO ABRINQ PELOS DIREITOS DA CRIANÇA. Núcleo de Assessoria, Planejamento e Pesquisa. Erradicação do Trabalho Infantil. Aplicação Experimental e Desenvolvimento de uma Metodologia para Monitoramento e Avaliação de Programas [S.1.] Dez. 2002. 90p. (Coordenado por Carlos Amaral).

IVO, A.B.L. Metamorfoses da Questão Democrática (Governabilidade e Pobreza). Buenos Aires: CLACSO, 2001. 205p.

MAGRI, C. Dilemas e peculiaridades do Programa de Erradicação do Trabalho Infantil. In: ARREGUI, C.O. (Org.). Erradicação do trabalho infantil. Dimensionando as experiências de Pernambuco, Mato Grosso do Sul e Bahia. São Paulo: Evoé, 2000. p.53-58.

NEVES, D.P. A Perversão do Trabalho Infantil. Lógicas Sociais e Alternativas de Prevenção. Niterói: Intertexto, 1999. 241p.

PROGRAMA DE ERRADICAÇÃO DO TRABALHO INFANTIL PETI. Manual de Orientações. Brasília: Seas, 2002.

PROJETO PROSPERAR. Emprego e Renda para as Famílias do Peti - Bahia. Comissão Estadual de Prevenção e Erradicação do Trabalho Infantil, da Bahia, Movimento de Organização Comunitária. Secretaria do Trabalho e Ação Social do Estado da Bahia, [S.1.] [s.d.].

PUTNAM, R.C. Comunidade e Democracia. A experiência da Itália Moderna. Rio de Janeiro: Editora Fundação Getúlio Vargas, 1996.

RAMOS, A.R.N.; NASCIMENTO, A.D. Resgatando a Infância. A trajetória do Peti na Bahia. Salvador: MOC/OIT/Unicef, 2001. 88p.

SOUZA, F.F. de. Informe da Comissão Estadual de Erradicação do Trabalho Infantil na Bahia. In: ARREGUI, C.O. (Org.). Erradicação do trabalho infantil. Dimensionando as experiências de Pernambuco, Mato Grosso do Sul e Bahia. São Paulo: Evoé, 2000. p.91-98.

SOUZA, J.F. de; SOUZA, A.L.F. Crianças e Adolescentes. Futuro da Região Sisaleira da Bahia? Feira de Santana: Nupep/MOC, 2003. $255 \mathrm{p}$.

TRIBUNAL DE CONTAS DA UNIÃO; Secretaria de Fiscalização e Avaliação de Programas de Governo. Programa de Erradicação do Trabalho Infantil - Peti. Relatório de Auditoria de Natureza Operacional. Brasília: fev. 2002.

UNICEF. Relatório da Situação da Infância e Adolescência Brasileiras: diversidade e eqüidade. [S.1.] [s.d.].

Inaí Maria Moreira de Carvalho: Pesquisadora do Centro de Recursos Humanos e Professora do Programa de Pós-Graduação em Ciências Sociais da Universidade Federal da Bahia. Bolsista do CNPq. 